\title{
Textuality in 3D: three-dimensional (re)constructions as digital scholarly editions
}

\section{Susan Schreibman ${ }^{1} \cdot$ Costas Papadopoulos $^{1}$}

Published online: 14 May 2019

(C) The Author(s) 2019

\begin{abstract}
3D (re)constructions of heritage sites and Digital Scholarly Editions face similar needs and challenges and have many concepts in common, although they are expressed differently. 3D (re)constructions, however, lack a framework for addressing them. The goal of this article is not to create a single or the lowest common denominator to which both DSEs and 3D models subscribe, nor is it to reduce 3D to one scholarly editing tradition. It is rather to problematise the development of a model by borrowing concepts and values from editorial scholarship in order to enable public-facing 3D scholarship to be read in the same way that scholarly editions are by providing context, transmission history, and transparency of the editorial method/decision-making process.
\end{abstract}

Keywords 3D - (Re)construction · Digital scholalry editions · 3D scholarly editions · Ambiguity $\cdot$ Transparency $\cdot$ Evidence

\section{Introduction}

The nature, functionality, and theories informing Digital Scholarly Editions (DSEs) have flourished over the past three decades, moving beyond how to represent printbased texts in digital forms into new types of knowledge production and dissemination informed by the affordances of the medium (Apollon et al. 2014; Sutherland 1997; Driscoll and Pierazzo 2016; Pierazzo 2015). The creators of the earliest DSEs were cognizant of these differences in the nomenclature used to describe their scholarship: The Rosetti Archive, The Blake Archive, The MacGreevy Archive, The Whitman Archive. The shift from conceiving of their scholarship as an editorial product for print publication to web-based carried with it a new spatiality in which variants, versions, and secondary sources did not have to be decomposed into a notational shorthand

Susan Schreibman

s.schreibman@maastrichtuniversity.nl

1 Department of Literature \& Art, Faculty of Arts and Social Sciences, Maastricht Uiversity,

Maastricht, The Netherlands 
delivered at the bottom of the page, but rather connoted a shift in thinking of scholarly editions from sites of textual compression to decentred webs of textuality (after all, this was the height of hypertext theory). In Derridean terms, the digital archive was a space for gathering together texts on a specific theme, individual, or topic, expanding the world of its creation into an archontic space for inscription and investigation (Derrida and Prenowitz 1995, 10).

These new forms of editions could be also described as assemblages, little machines of knowledge (Deleuze and Guattari 1987, 4). Thinking of DSEs as machines of knowledge which represent texts as open objects that can be read and understood through and by their means of production and reception reelevates long-standing textual practices such as annotation, apparatus, and commentary as interlinked discourses, 'not in serially additive arrangements, but in functional interdependence', providing a palette for both textual and contextual study (Gabler 2010, 46). This model of DSEs repositions the editor, not as an objective arbiter of the text, but more like a hunter-gatherer, a constructor of a dynamic and rhizomatic knowledge site.

These knowledge sites need not privilege the alphanumeric. As early as 1999, when the first digital archives were being published, McKenzie described the panoply of objects that could be open to the kinds of intensive bibliographical study (transmission, production, and reception) that textual scholars had traditionally reserved for print and manuscript traditions, 'as verbal, visual, oral and numeric data' (McKenzie 1999, 13). Like McKenzie, we believe that the digital provides us with a pan-glossary to abstract the material medium of the objects of our contemplation to conceptual ones, and that the text(s) at the centre (or periphery) of the knowledge site we create is worthy of representing any human activity, not simply the artistic but the anthropologic. In his definition of digital scholarly editions, Sahle has also advocated that Scholarly Digital Editions not be restricted to literary texts but rather 'cover all cultural artefacts from the past that need critical examination in order to become useful sources for research in the humanities' (Sahle 2016, 22). What is key, however, is not simply that the object, or what we are broadly calling the 'text', is digitised and distributed electronically, but that it exists within a knowledge site, what we are calling a Digital Scholarly Edition; what Derrida (Derrida and Prenowitz 1995, 10) and the earliest textual editors of web-based scholarship called the archive, what Deleuze and Guattari $(1987,4)$ called the assemblage, and McKenzie $(1999,15)$ 'the sociology of texts', integrating interrogating and interlinking, the textual and the contextual (Gabler 2010, 46).

At first glance, conceiving of three-dimensional (3D) (re)constructions as Digital Scholarly Editions might seem anti-intuitive. After all, the technologies, methodologies, and theories that have informed the creation of DSEs, everything from TEI/ XML, documentary vs critical editions, and relational vs XML-aware databases to more recent discussions of how the texts created in DSEs can be repurposed, remodelled, and algorithmically analysed and visualised, share little with the technologies, methodologies, and theories that have informed scholarship expressed through 3D reconstructions. 3D reconstructions are computer generated models produced in computer graphic software packages. They represent in three dimensions geometric data combined with textures and a simulation of how light interacts with different surfaces.

The $3 \mathrm{D}(\mathrm{re})$ constructions we refer to in this article concern cultural heritage visualisations and simulations. These visualisations range from schematic 
representations of buildings to photorealistic renderings and predictive simulations of ancient structures (see Dawson et al. 2007) and from spatial analysis (see Paliou et al. 2011) and physics simulations (see Oetelaar 2016) to interactive virtual worlds utilising online platforms (see Sequiera and Morgado 2013) and game engines (see the projects carried out as part of the Humanities Virtual Worlds Consortium - http://virtualworlds. etc.ucla.edu/). Examples of the types of projects that could be informed by the principles outlined in this article include the Virtual Rosewood Research project (http://www.rosewood-heritage.net/), which focuses on Rosewood, Florida, an African American town destroyed during the 1923 race riot (González-Tennant 2015 ), Virtual Williamsburg 1776 (Fischer 2012; http://research.history.org/vw1776/), and Digital Hadrian's Villa (Frischer and Stinson 2016), the Unity version of which allows users to test archaeoastronomical theories (e.g. the alignment of the sun with the tower of Roccabruna on the summer solstices during Hadrian's reign to discover celestial arrangements in the night sky as they would have been seen in the past). It also includes Contested Memories: The Battle of Mount Street Bridge project (http://mountstreet1916.ie), which will be discussed at the end of this article.

We will be utilising the term (re)constructions (as opposed to reconstruction) to signify the theoretical nature of the research being undertaken, reinforcing the hypothetical nature of the models created as described in more detail below. Although threedimensional modelling has been seen as an essential research practice in fields such as archaeology and architecture, with hundreds of applications providing opportunities for experimentation and new insights, it has never assumed a central role or been established as scholarship in its own right, and it has been less frequently used by other fields in the humanities. There is no doubt that these models can have a 'wow' factor, and they are commonly used as the last step that takes place at the end of a project as a means of communicating absence in a visually engaging way (Hermon and Fabian 2002; Gillings 2005) and attracting publicity and funding. The situation is changing, however, as the cost of the technologies and equipment needed to create 3D models has become more affordable, and more institutions at third level teach the skills, methods, and theories involved. Over a decade ago, Gillings $(2005,224)$ called for a robust theoretical and conceptual framework that would realise the potential of the method, providing a means of making visible the underlying decision-making process while disseminating research findings within a single methodological framework. That framework still does not exist.

Today 3D (re)constructions are being used as analytical tools within the broad area of history and heritage studies to explore the impact of light on the experience and perception of ancient environments, as simulations to investigate how battles unfold, as a means of providing an embodied and sensorial understanding, and as immersive experiences of a period, culture, or historical event. In most cases these (re)constructions have been created for offline use due to the computational power required to undertake various analyses or even to host the worlds online, making it difficult for researchers outside project teams to learn from the work of others. It may be due to these difficulties that those working with these technologies have spent less time developing a framework within which to convey to a wider public the scholarship that has gone into the creation of the (re)construction, including the choices used in creating the model, the methodologies used, the history of the subject under investigation, and the decisions made during the process of its creation. 
Current 3D scholarship primarily exists in a bifurcated information space. The models exist electronically, but the knowledge generated from them is written about in journal articles, illustrated by static two-dimensional images, while the models themselves cannot be accessed beyond the individual or the team who worked on them. While 15 years ago Earl and Wheatley (2002) ascribed the under-theorisation of the field to a widespread belief that $3 \mathrm{D}$ visualisation had a small role to play as an interpretive mechanism, there now is a growing body of practitioners in a wide variety of fields who are looking for a holistic information environment within which to disseminate their work.

The authors of this article, one with a background that stretches back to scholarly editing in print and, since the mid-1990s, has included digital forms and the other with a background in digital archaeology and particularly in the use of $3 \mathrm{D}$ modelling for analytical and documentary purposes, have come to believe that recent scholarship in digital scholarly editions, as it moves away from the conceptual and medium-specific frameworks of print traditions into more dynamic knowledge sites, can provide a productive model of the ways in which 3D (re)constructions can be used to reach larger audiences and shape intellectual debates. This scholarship can also provide a model for the ways in which the knowledge gained by the researchers who created it can be embedded in 3D (re)constructions.

This is a speculative article, the essential intention of which is to propose and test theories from two domains which at first glance seem to have very little in common. However, its authors have come to realise after several years of collaboration and conversation that they share significant concerns and have wrestled with similar concepts, from expressing transparency and ambiguity to modelling absence from the extant record. This is an opening salvo to generate discussion about how the current theories about DSEs could be expanded and applied beyond their dominantly textbased practice and how 3D (re)constructions can be conceived of as open knowledge networks which contain, embedded within them, the analytical and archival scholarship that informed their creation. ${ }^{1}$

\section{Modelling in 3D: an introduction}

Three-dimensional computer graphical approaches flourished in the television and film industry with the first commercial 3D software package, Wavefront Technologies, released in 1984 to serve the increasing needs of motion pictures. Around the same

\footnotetext{
${ }^{1}$ This article has grown out of present and previous conversations. The authors thank the participants in the Virtual Worlds as Digital Scholarly Editions Masterclass (Maynooth University, 13-14 June 2017, http://dhprojects.maynoothuniversity.ie/vwdse/, funded by the Digital Scholarly Editions Initial Training Network (DiXiT). This Masterclass provided a fruitful dialogue between scholars from the fields of heritage 3D visualisation and Digital Scholarly Editing, allowing them to explore theoretical and practical issues pertaining to the creation, annotation, and publication of 3D models with the ultimate aim of marrying the practices of the two communities. The authors are also part of the Andrew W. Mellon Foundation project 'Scholarship in 3D: Digital Edition Publishing Cooperative', which attempts to build a sustainable framework within which to reconceive $3 \mathrm{D}$ works as digital editions and create an infrastructure that will enable its recognition as scholarship.
} 
time, 3D modelling was used to (re)construct heritage datasets, with the earliest reported work being that of the bath building at Caerleon Roman Fort in South Wales (Smith 1985) and a year later the first animated virtual tour, that of the Old Minster of Winchester (Reilly et al. 2016).

In this paper, we focus on the type of 3D modelling in which computer graphics are used to (re)construct 'what is not there' as a means of providing a better understanding of and generating hypotheses concerning and interpretations of different datasets, from ancient structures to twentieth-century buildings. Like textual scholarship, 3D modelling requires evaluations of the reliability of different, often incomplete and ambiguous sources, and it gathers evidence that leads to a series of decisions regarding the type, amount, and style of models to be constructed, depending on their intended uses and audiences.

The 3D scholarship to which we are referring in this paper has been called by many names, from three-dimensional (solid) modelling to virtual reconstructions and 3D computer graphic simulations. These terms have emerged from particular schools of thought, theoretical and methodological traditions, and biases and assumptions. For example, the term Virtual Reconstruction became popular in the 1990s after Reilly (1991) coined the term Virtual Archaeology, while in the mid-2000s the term Virtual Worlds was used to reflect online, multiplayer, avatar-based game approaches (see for example Bell 2008; Nevelsteen 2017), facilitated by platforms such as Second Life, Open Simulator, and Unity. In these three decades, no consistency or consensus emerged concerning the terminology used to describe this type of scholarship; some consistency has only been seen in the association of these terms with the word reconstruction.

The fallacy of the term 'reconstruction' (Taylor 1948; Clark 2010) is ingrained in the practice of many disciplines. For example, in archaeology under the influence of the processual school, emphasis was placed on the objectivity of scientific methods, while in textual editing, according to the American school, particularly within the Bowers/ Tanselle approach, the goal of the edition is to restore the text to the author's final intention (Shillingsburg 1999, 29). Reconstruction implies an attempt to bring something back to its original state based on available evidence as its starting point. However, such attempts can never be accurate, as they are interpretations of some past reality or of the documentary evidence, and as such, they reflect present-day social and cultural agendas.

Much as editing texts for digital publication has made editors aware of the constraints of editing for print publication (McGann 1997, 20) coupled with new theoretical approaches which do not favour (re)construction of the text according to what the editor believes the author would have intended. Equally, the possibility of photorealistic rendering of $3 \mathrm{D}$ heritage opened up new debates as to the purpose and role of $3 \mathrm{D}$ models in the interpretive process (Gillings 2005). Calling what we model a 'reconstruction' which is indistinguishable from real life (as in the case of 3D) or professing to know what a long-dead author wanted (in terms of textual editing) leave little room to question the process according to which the 'reconstruction' was made, the authenticity of the new work that has been created, or the reliability or interpretation of the evidence used in its construction. Therefore, we use the term (re)construction to emphasise the decision-making process and the non-absolutist approach in the construction of the model. 


\section{3D and textual scholarship: a parallel path}

Scholars in both textual editing and 3D (re)constructions have faced similar issues in modelling the textual/material record, and surprisingly, they have employed either the same or similar terminology in confronting these challenges. This is what we refer to as 'a parallel path'. These issues concern the use of evidence, ways of making the decision making process visible, and ways of dealing with ambiguity. In this section we outline these parallels, which form the key features of the last section, Towards 3D Digital Scholarly Editions.

\subsection{Evidence}

Both fields work to reconstruct the text on the basis of existing, albeit imperfect evidence (if the evidence were perfect, there would be no need for editors or editions). In both cases, the researcher is evaluating the evidentiary record, and the further we go back in this record chronologically, the less evidence remains. In many respects, the 3D (re)constructions of ancient spaces are more akin to the textual editing tradition of stemmatics applied to premodern texts, in which the editor reconstructs the original text by working backwards from extant witnesses through a set of relationships expressed as a tree structure in an effort to come as close as possible to the original text before it was corrupted (or indeed thought to be improved) through the copying process.

3D (re)constructions of sites that exist in fragmentary form, e.g. a prehistoric settlement, also go through a process of evaluation of extant data, resolving, discarding, and harmonising evidence in an effort to understand what might have existed. This can be likened to an interpretation of secondary sources documenting remains in the form of textual records/field notes, photographs, and illustrations, site-specific physical remains, and information coming from other sites which bear some resemblance (temporal or spatial) to the subject under investigation. The goal in both fields is the (re)construction of an artefact (be it a poem or an ancient building) which makes clear to the user where there are gaps in knowledge of the putative original and what methods and evidence were used in order to fill these gaps.

On the other hand, 3D (re)constructions based on (nearly) complete evidence, e.g. (re)constructions of a twentieth-century urban battlefield in which old buildings still stand, share more with traditions and methods used to edit nineteenth-century and twentieth-century texts. In both cases, there tends to exist an abundance of evidence, and the researcher adjudicates among extant sources, each of which carries its own authority. Just as texts can exist in multiple versions, manuscripts, typescripts, and printings, some or all of which might have been authorised by the writer, bringing back in $3 \mathrm{D}$ a building or a street or what happened in that space at a specific point in time (or indeed, over time) may utilise a plethora of evidence, including documentary, oral, and visual. This evidence may be contradictory and fragmentary, and some items of evidence may be more 'authorised' or credible than others.

The theories underlying the textual tradition of versioning in which the goal is not to establish a definitive or reading text, but to reconstruct, not only a textual history, but the underlying view of the nature of the text's production (Tanselle 1995, 24) might prove a useful foundation for models of 3D (re)constructions in which what is of interest is the potential to make visible multiple states over time or alternative 
possibilities in interpretation. These 'textual' moments can be viewed as snapshots, each providing a unique, equally valid window onto the past (Schreibman 1993, 93). Textual editors have the ability to model these differences in TEI/XML within one apparatus or framework explicitly to denote regions of both shared and divergent text. Once these regions are marked, they can be analysed and visualised, providing the modeller with a method for recording difference over time and the reader with a standard notation for the decision making process. While TEI/XML is not a suitable language for $3 \mathrm{D}$, the theoretical framing may well be, as it offers a way to make variation visible within a single model.

\subsection{Ambiguity}

The Oxford English Dictionary defines ambiguity as the 'quality of being open to more than one interpretation; inexactness'. It is precisely because of the ambiguous nature of evidence that textual scholarship exists. Revealing, acknowledging, and/or resolving this ambiguity is part of the interpretive process. In the transition from print to digital editing of alphanumeric texts, it has become possible to represent ambiguity more explicitly in a non-notational manner, providing the reader with the documentary evidence to mediate between different textual states (Schreibman 2002, 288-89). There have been lengthy discussions concerning the contention that simply providing the reader with facsimiles of the various witnesses is a form of unediting (Schreibman 2013), i.e. an abdication of the editorial role. On the other hand, modelling the text according to a theory such as genetic editing or versioning to make visible the writing process allows readers to formulate their own sense of the work (or work-in-progress) situated in both time and place (Machan 1994, 303). In other words, the point of this type of editing is not to resolve the ambiguity of the textual record, but to expose it through modelling.

Modelling ambiguity has been the subject of much discussion in 3D (re)constructions. While in both fields there exists the subjective nature of gathering, selecting, and interpreting evidence, with 3D (re)constructions there are less codified ways to express ambiguity (or indeed to consider whether or not it should be expressed) and to make the modelling process as transparent as possible (for a recent discussion see Watterson 2015). Representing ambiguity began to become more pressing in the mid-1990s and especially in the 2000 s, as photorealistic models started dominating heritage representation. This, in turn, fuelled debates about their misleading nature (Miller and Richards 1995; James 1997; Goodrick and Gillings 2000; Eiteljorg 2000) and the problematic use of the word 'reconstruction' (Clark 2010). These concerns gave rise to a series of proof-of-concept implementations that demonstrated intellectual rigour in 3D models and explicated decision-making in the process of their creation as a means of counteracting their problematic photorealistic nature. These implementations included alternative reconstructions, annotations, renderings in different colours, textures, and shadings, as well as ways of activating or deactivating ambiguous features and alternative models that would in turn affect other elements (Kensek 2007).

Unlike the digital scholarly editing practices in which there exists a core set of technologies and methods (largely around XML/TEI), to a large extent 3D visualisations utilise bespoke solutions with no sustainable platforms, methodologies, or standards which might lead to the wider adoption of such practices (see for example: 
Archaeology Data Service Guide to Archiving Virtual Reality Projects (2018): http://guides.archaeologydataservice.ac.uk/g2gp/Vr_6-1; McDonough et al. 2010). The World Wide Web currently hosts a wide variety of DSEs, some going back to the earliest digital archives in the mid-1990s, providing the field with a tradition from which new theories, models, and editions are developed. However, due to their intensive computational nature, most 3D visualisation projects are developed for offline use and in a constantly changing environment in which software and frameworks become obsolete soon after their release. Also, the Internet itself, with constant changes to browsers, does not offer a stable environment for such projects (Ruan and McDonough 2009), providing little opportunity to build a body of knowledge and a practice-based community.

\subsection{Transparency}

As mentioned above, the creation of 3D models under the influence of photorealism gave birth to a series of debates regarding transparency, documentation of decisionmaking, standards, and intellectual rigour in the process of (re)construction. Earlier, more schematic work did not carry with it the same calls for transparency, as it did not, however unintentionally, 'trick' the viewer into reading reality into the (re)construction. Several projects attempted to establish principles to address this new environment. The best-known is the London Charter (Denard 2009; http://www.londoncharter.org/), developed in 2006 at a meeting of 3D visualisation specialists who came up with a series of principles that would ensure a certain level of standardisation in terms of the creation of documentation, ensuring sustainability and access and articulating the aims and methods of (re)creation (Denard 2012). For example, principle 4.6, 'Documentation of Process (Paradata); states that:

Documentation of the evaluative, analytical, deductive, interpretative and creative decisions made in the course of computer-based visualisation should be disseminated in such a way that the relationship between research sources, implicit knowledge, explicit reasoning, and visualisation-based outcomes can be understood (Denard 2009, 8-9).

While a worthy goal, it is impossible not only to document, but, as was found in editing according to the Greg/Bowers (Bowers 1978) school of copy-text, even to represent each and every editorial decision and the rationale for that decision. This would amount to providing a textual record of not only how each accidental (e.g. punctuation, spelling, word division which was considered less significant and meaning-making than substantives, e.g. word choice) was handled, but why it was handled that way. In both traditions, this goal becomes even more unobtainable, as it would involve a full time amanuenses following the researcher (or team of researchers), recording every conversation, saving every version of every document, every state of every electronic file. Even if it were possible to save all this, how could it be presented to the reader so as to make more transparent the decision-making process? This might be more akin to an archive or an assemblage, but even if this could be ordered and catalogued, what it does not necessarily demonstrate is what happens in the space between the evidence, 
the ideas that inform the decision-making process, tracing a path from evidence to its representation.

Despite the fact that several reports and frameworks followed The London Charter, ${ }^{2}$ none of them tackled the inherent visual illiteracy in reading photorealistic 3D visualisations as texts. There is no scaffolding within which the $3 \mathrm{D}$ model is situated to provide the reader with access to its conceptual and methodological underpinnings.

\section{Towards 3D scholarly editions}

We have argued that Digital Scholarly Editions act as mediators and gatherings of evidence (Gabler 2010, 44), textual, social, and historical, that is read in an increasingly multimodal infrastructure. As knowledge sites, they encompass within the same computational paradigm both the primary text and the evidence that informed the decisions in creating the text, thus providing the community which it serves a tool for 'prying problems apart and opening up a new space for the extension of learning' (Apollon et al. 2014, 5-6). This framework provides the information structures and evidence that make up the edition so that the audience can understand the process behind the creation of the edition and adjudicate its authenticity and reliability.

Hence we believe that there exists a case and a rationale for designing a blueprint to link editorial, epistemological, and technical practices in the development of editions of $3 \mathrm{D}$ (re)constructions as scholarship in its own right, as assessable assemblages to combat the problem of the vacuous nature of most models: empty sites where the research that went into their creation remains invisible to those outside project teams. While photorealistic models are ever more beautiful to behold, if their raison d'etre is not to serve as works of art, but as mediators of evidence, the ways in which the chain of production that informed their creation needs to be made visible in the same information space as the models. We are not advocating that a DSE of a 3D (re)construction be thought of as a defined object, but rather as a methodological field in which a set of codes imposes a prefiguring frame on the reality being created, and not only the technological codes that govern the creation of this reality, but also the social, theoretical, and historical codes that its makers adopt in its creation (Barthes 1977).

The construction of such an edition entails building an intertextual network composed of the 3D model along with its accompanying annotation and apparatus, thus providing a base from which the reader can actively engage in the knowledge creation process. This approach is being taken in the redevelopment of the Contested Memories: The Battle of Mount Street Bridge (BMSB) project, a spatiotemporal (re)construction of one of the most important battles during the 1916 Easter Rising between a small

\footnotetext{
${ }^{2}$ Pletinckx (2007) and the Network of Excellence, Epoch developed the Interpretation Management KnowHow booklet, which explained different methods, including source assessment and correlation, hypotheses trees, and updating, to ensure scholarly transparency in 3D visualisation. This information and the comments, decisions, and interpretive processes comprise the paradata of the project (Baker 2012, 163-176), which allows a clearer interpretation management and understanding of the relationships between primary data and the outcome. More recently, The Seville Principles (Lopez-Menchero and Grande 2011) used the London Charter as a theoretical framework to develop a series of principles to increase the applicability of the latter to $3 \mathrm{D}$ visualisations of archaeological heritage. Other works have also elaborated on how scientific reasoning can become visible (Hermon 2012; Niccolucci 2012).
} 


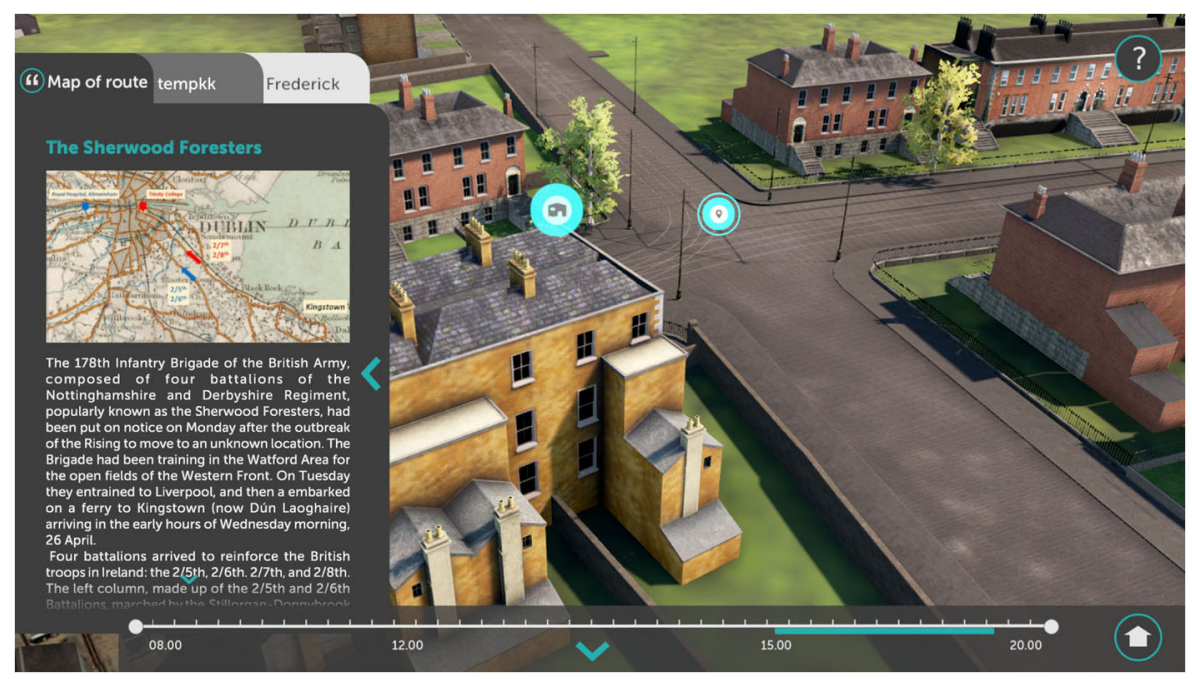

Fig. 1 The new user interface of the standalone Unity 3D environment includes an annotation panel that provides contextual information (text and/or multimedia) activated by hotspots, as well as a timeline for exploring the battle temporally.

group of Irish Volunteers (17) and a much larger force (1750) of British soldiers (https://mountstreet1916.ie/ Papadopoulos and Schreibman in press).The apparatus being explored includes a narrative-driven camera with a voice over providing an evidence-informed interpretation of how the battle unfolded; audio files that replicate the types of sounds that accompanied the battle; and a user interface to display in-world textual annotations about the combatants and other participants (such as the medical personnel), key buildings and events, the types and makes of guns used, and the sources for the (re)construction (from the methods used to the primary sources consulted; see Fig. 1 for a mock up). The project has also experimented (see Fig. 2) with animated agents to help the reader better visualise troop movements as the battle unfolded.

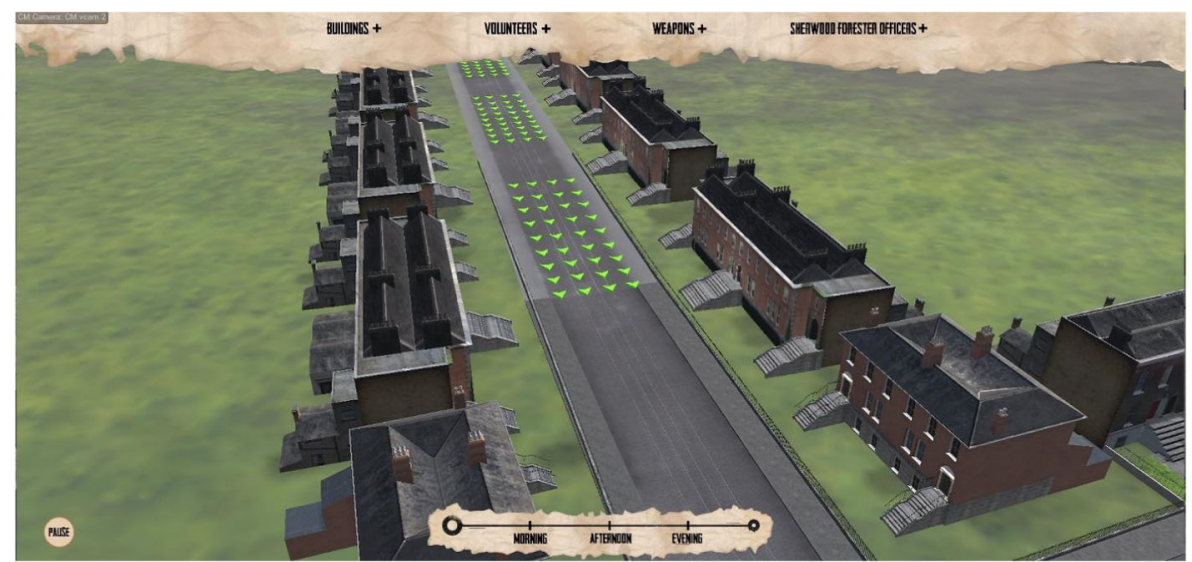

Fig. 2 A total of $252 \mathrm{AI}$ agents (36 for each of the seven companies of British soldiers) have been included in a WebGL version of the 3D model 
Embedding the iconography of 3D (re)constructions into what we might broadly describe as scholarly editing practice, opens up new vistas for scholarship and the communication of the results of that scholarship within spatio-temporal environments that are immersive and multisensorial. If the goal of the modelled dataset is to create its own ecosystem to provoke and encourage evolving thought about the materials, aesthetics, and cultures it simulates (Schreibman 2013), then the scholarly editing framework we have outlined here, we believe, fulfils that goal.

The real difference between the two domains is not the technologies utilised in digital production, but the fact that textual editors have a long history of models, theories, and paradigms of the documentation and display of text and paratext (as well as models, theories, and paradigms for the fashioning of arguments), and 3D (re)constructions do not. This article presents a rationale for the development of such as framework.

Open Access This article is distributed under the terms of the Creative Commons Attribution 4.0 International License (http://creativecommons.org/licenses/by/4.0/), which permits unrestricted use, distribution, and reproduction in any medium, provided you give appropriate credit to the original author(s) and the source, provide a link to the Creative Commons license, and indicate if changes were made.

\section{References}

Apollon, D., Bélisle, C., \& Régnier, P. (2014). Digital critical editions. Urbana: University of Illinois Press. Archiving Virtual Reality Projects. (2018) Archaeology Data Service / Digital Antiquity. Guides to Good Practice. Retrieved from http://guides.archaeologydataservice.ac.uk/g2gp/Vr_6-1. Accessed 2018, March.

Baker, D. (2012). Defining Paradata in heritage visualisation. In A. Bentkowska-Kafel, H. Denard, \& D. Baker (Eds.), Paradata and transparency in virtual heritage (pp. 163-176). Fanrham: Ashgate.

Barthes, R. (1977). Image-music-text. Essays selected and translated by Stephen heath. London: Fontana.

Bell, M. (2008). Toward a definition of "virtual worlds". Journal of Virtual Worlds Research 1(1). Retrieved from https://journals.tdl.org/jvwr/index.php/jvwr/article/view/283/237. Accessed 2018, March 6.

Bowers, F. (1978). Greg's 'rationale of copy-text' revisited. Studies in Bibliography, 31, 90-161.

Clark, J. T. (2010). The fallacy of reconstruction. In Forte, M. (Ed.), Cyber-Archaeology (pp. 63-73). BAR International Series S2177. Oxford: Archaeopress.

Dawson P., Levy, R., Gardner, D. \& Walls, M. (2007). Simulating the behavior of light inside Arctic dwellings: Implications for assessing the role of vision in task performance. World Archaeology 39, pp. 17-55. Retrieved from https://doi.org/10.1080/00438240601136397. Accessed 2018, March 6.

Deleuze, G., \& Guattari, F. (1987). A thousand plateaus: Capitalism and schizophrenia. London: University of Minnesota Press.

Denard, H. (ed). (2009). The London charter. Retrieved from http://www.londoncharter.org/. Accessed 2018, March 10.

Denard, H. (2012). A new introduction to the London charter. In A. Bentkowska-Kafel, D. Baker, \& H. Denard (Eds.), Paradata and transparency in virtual heritage (pp. 57-71). Brookfield: Ashgate.

Derrida, J. \& Prenowitz, E. (1995). Archive fever: A Freudian impression. Diacritics 25(2), 9-63. Retrieved from http://www.jstor.org/stable/465144. Accessed 2018, March 6.

Driscoll, M., \& Pierazzo, E. (2016). Digital scholarly editing: Theories and practices. Cambridge: Open Book Publishers.

Earl, G., \& Wheatley, D. W. (2002). Virtual reconstruction and the interpretative process: A case-study from Avebury. In D. W. Wheatley, G. Earl, \& S. Poppy (Eds.), Contemporary themes in archaeological computing (pp. 5-15). Oxford: Oxbow.

Eiteljorg, H. (2000). The compelling computer image - A double-edged sword. Internet Archaeology 8. Retrieved from http://intarch.ac.uk/journal/issue8/eiteljorg_index.html. Accessed 2018, March 6.

Fischer L. (2012). Visualizing Williamsburg: Modeling an early American City in 2D and 3D. In Niccolucci, F., Dellepiane, M., Pena Serna, S., Rushmeier, H. \& Van Gool, L. (Eds.), VAST11: International 
Symposium on Virtual Reality, Archaeology and Intelligent Cultural Heritage (pp. 77-80. The Eurographics Association, 2011. Retrieved from https://doi.org/10.2312/PE/VAST/VAST11S/077-080. Accessed 2018, March 6.

Frischer B. \& Stinson, P. (2016). The importance of scientific authentication and a formal visual language in virtual models of archaeological sites: The case of the house of Augustus and villa of the mysteries. In Silberman, N. A. \& Callebaut, D. (Eds.), Proceedings of the Interpreting the Past: Heritage, New Technologies and Local Development Conference on Authenticity, Intellectual Integrity and Sustainable Development of the Public Presentation of Archaeological and Historical sites and Landscapes (pp. 4983). Brussels: Flemish Heritage Institute. Retrieved from http://www.iath.virginia. edu/images/pdfs/frischer_stinson.pdf. Accessed 2018, March 6.

Gabler, H.W. (2010). Theorizing the digital scholarly edition. Literature Compass 7, pp. 43-56. Retrieved from https://doi.org/10.1111/j.1741-4113.2009.00675.x. Accessed 2018, March 6.

Gillings, M. (2005). The real, the virtually real, and the hyperreal: The role of VR in archaeology. In Smiles, S. \& Moser, S. (Eds.), Envisioning the past: Archaeology and the image. Oxford: Blackwell Publishing. https://doi.org/10.1002/9780470774830.ch12. Accessed 2018, March 6.

González-Tennant, E. (2015). Resurrecting Rosewood: new heritage as applied visual anthropology. In A. Gubrium, K. Harper, \& M. Otanez (Eds.), Participatory visual and digital research in action (pp. 163180). Walnut Creek: Left Coast Press.

Goodrick, G., \& Gillings, M. (2000). Constructs, simulations and hyperreal worlds: The role of virtual reality (VR) in archaeological research. In G. Lock \& K. Brown (Eds.), On the theory and practice of archaeological computing (pp. 41-58). Oxford: Oxford University Press.

Hermon, S. (2012). Scientific method, Chaîne Opératoire and visualisation: 3D modelling as a research tool in archaeology. In A. Bentkowska-Kafel, H. Denard, \& D. Baker (Eds.), Paradata and transparency in virtual heritage (pp. 13-22). Farnham: Ashgate.

Hermon, S. \& Fabian, P. (2002). Virtual reconstruction of archaeological sites, some scientific considerations: Avdat Roman military camp as a case-study. In Niccolucci, F. (Ed.), Virtual archaeology: Proceedings of the VAST Euroconference (pp. 103-108). Arezzo 2000, November 24-25. Oxford.

James, S. (1997). Drawing inferences. In L. B. Molyneaux (Ed.), The cultural life of images: Visual representation in archaeology (pp. 22-48). Great Britain: Routledge.

Kensek, K. (2007). Survey of methods for showing missing data, multiple alternatives, and uncertainty in reconstructions. CSA Newsletter 19 (3). Retrieved from http://csanet.org/newsletter/winter07/nlw0702. html. Accessed 2018, March 6.

Lopez-Menchero, V.M. \& Grande, A. (2011). Principles of Seville. International Principles of Virtual Archaeology. Forum Internacional de Arqueología Virtual. Retrieved from http://www. arqueologiavirtual.com/carta/wp-content/uploads/2012/03/BORRADOR-FINAL-FINAL-DRAFT.pdf. Accessed 2018, March 6.

Machan, T. W. (1994). Chaucer's poetry, versioning and hypertext. Philological Quarterly, 73(3), $299-316$.

McDonough, J., Olendorf, R., Kirschenbaum, M., et al. (2010). Preserving virtual worlds final report. Illinois: IDEALS: Illinois digital environment for access to learning and scholarship. Retrieved from http://hdl. handle.net/2142/17097. Accessed 2018, March 6.

McGann, J. (1997). A rationale of hypertext. In K. Sutherland (Ed.), Electronic text: Investigations into method and theory (pp. 19-46). Oxford: Clarendon Press.

McKenzie, D. F. (1999). Bibliography and the sociology of texts. Cambridge: Cambridge University Press.

Miller, P., \& Richards, J. (1995). The good, the bad, and the downright misleading: Archaeological adoption of computer visualization. In J. Huggett \& N. Ryan (Eds.), Computer applications and quantitative methods in archaeology 1994 (pp. 19-22). Oxford: BAR International Series 600.

Nevelsteen, K. (2017). Virtual world, defined from a technological perspective, and applied to video games, mixed reality and the Metaverse. Computer Animation \& Virtual Worlds. Retrieved from https://doi. org/10.1002/cav.1752. Accessed 2018, March 12.

Niccolucci, F. (2012). Setting standards for 3D visualisation of cultural heritage in Europe and beyond. In A. Bentkowska-Kafel, H. Denard, \& D. Baker (Eds.), Paradata and transparency in virtual heritage (pp. 23-36). Farnham: Ashgate.

Oetelaar, T. (2016). CFD, thermal environments, and cultural heritage: Two case studies of Roman baths. In IEEE 16th International Conference on Environment and Electrical Engineering (EEEIC), Florence, Italy: IEEE. Retrieved from https://doi.org/10.1109/EEEIC.2016.7555484. Accessed 2018, March 6.

Paliou, E., Wheatley, D., \& Earl, G. (2011). Three-dimensional visibility analysis of architectural spaces: Iconography and visibility of the wall paintings of Xeste 3 (late bronze age Akrotiri). Journal of Archaeological Science, 38(2), 375-386. https://doi.org/10.1016/j.jas.2010.09.016 Accessed 2018, March 6. 
Papadopoulos, C. and Schreibman, S. (in press). Towards 3D Scholarly Editions: The Battle of Mount Street Bridge. Digital Humanities Quarterly.

Pierazzo, E. (2015). Digital scholarly editing: Theories, models and methods. New York: Ashgate.

Pletinckx, D. (2007). Interpretation management: How to make sustainable visualisations of the past, Epoch. Retrieved from http://media.digitalheritage.se/2010/07/Interpretation_Managment_TII.pdf. Accessed 2018, March 6.

Reilly, P. (1991). Towards a virtual archaeology. In Rahtz, S. \& Lockyear, K. (Eds.), CAA90. Computer Applications and Quantitative Methods in Archaeology 1990. British archaeological reports international series 565 (pp. 132-139). Oxford: Tempus Reparatum.

Reilly, P., Walter, A., \& Todd, S. (2016). Rediscovering and Modernising the digital old minster of Winchester. Digital Applications in Archaeology and Cultural Heritage, 3(2), 33-41. https://doi.org/10.1016/j. daach.2016.04.001 Accessed 2018, March 12.

Ruan, J. \& McDonough, P. (2009). Preserving born-digital cultural heritage in virtual world. In IEEE International Symposium on IT in Medicine \& Education (pp. 745-748). Jina, China, IEEEA, 2009, 745-748. Retrieved from https://doi.org/10.1109/ITIME.2009.5236324. Accessed 2018, March 6.

Sahle, P. (2016). What is a scholarly digital edition. In M. Driscoll \& E. Pierazzo (Eds.), Digital scholarly editing: Theories and practices (pp. 20-39). Cambridge: Open Book Publishers.

Schreibman, S. (1993). Re-envisioning versioning: a scholar's toolkit. In A. Ciula \& F. Stella (Eds.), Digital philology and medieval texts (pp. 93-102). Pisa: Pacini editore.

Schreibman, S. (2002). Computer-mediated texts and textuality. Computers and the Humanities 36: pp. 283293. Pisa: Pacini Editore.

Schreibman, S. (2013). Digital scholarly editing. In Price, K. \& Siemens, R. (Eds.), Literary studies in a digital age: A methodological primer. MLA Commons. Retrieved from https://dlsanthology.mla.hcommons. org/digital-scholarly-editing/. Accessed 2018, March 6.

Luis M. Sequiera \& Morgado, L. C. (2013). Virtual archaeology in second life and OpenSimulator. Journal of Virtual Worlds Research 6(1), pp. 1-16. Retrieved from https://journals.tdl.org/jvwr/index. php/jvwr/article/view/7047/6310. Accessed 2018, March 6.

Shillingsburg, P. (1999). Scholarly editing in the computer age: Theory and practice. Ann Arbor: the University of Michigan Press.

Smith, I. (1985). Romans make a high-tech comeback: Sid and Dora's bath show pulls in the crowd. Computing, June, 7-8.

Sutherland, K. (1997). Electronic text: Investigations in method and theory. Oxford: Clarendon Press.

Tanselle, G. T. (1995). The varieties of scholarly editing. In D. C. Greetham (Ed.), Scholarly editing: A guide to research (pp. 9-32). New York: Modern Language Association.

Taylor, W. W. (1948). A study of archeology. Memoir no 69. American Anthropologist, 50(3), Pt 2.

Watterson, A. (2015). Beyond digital dwelling: Re-thinking interpretive visualisation in archaeology. Open Archaeology 1 (1). Retrieved from https://doi.org/10.1515/opar-2015-0006. Accessed 2018, March 12. 